\title{
Attenuation of retroactive inhibition by a single electroconvulsive shock
}

D. R. JUSTESEN, Veterans Administration Hospital, Kansas City, Mo. 64128, J. T. BRAUCHI, Kansas University Medical Center, Kansas City, Kans. 66103, D. H. DODD ${ }^{2}$ and $C$. L. SHERIDAN, University of Missouri at Kansas City and Veterans Administration Hospital, Kansas City, Mo. 64128, and L. E. BOURNE, JR., University of Colorado, Boulder, Colo. 80302

A retroactively interfering reversal habit, a left or right turn in a single-unit water maze, was learned by 28 rats. The interpolated habit was immediately followed in 14 of the animals by a single electroshock convulsion. Reliable "interference with retroactive interference" was found: shock animals were superior in demonstrating retention of original learning. This finding is discussed with reference to major behavioral theories of ECS and interpreted as being more nearly supportive of amnesic, as opposed to fear-induction or competing-response, mechanisms.

The massive experimental literature on electroconvulsive shock continues to grow. Far from generating a better grasp of how convulsive shock works, however, it is spawning more and more theoretical controversy over its most frequently reported effect: disruption of recently learned habits. Presently contending hypothetical mechanisms are being couched in terms of retrograde amnesia, induction of fear, production of competing response tendencies, and retrieval (as opposed to memory) deficits (cf. Duncan, 1949; Glickman, 1961; McGaugh \& Petrinovich, 1966; Coons \& Miller, 1960; McIver \& Nielson, 1966; Adams \& Lewis, 1962; Lewis \& Maher, 1966; Nielson, 1968; Nielson, Justesen, \& Porter, 1969).

From the standpoint of the traditional original-learning, presentation-of-shock, retention-measure sequence, the paradigm that has been used in most animal studies of convulsive shock, any or all of these proposed mechanisms could result in retention deficits: a convulsive shock might cause the animal to forget, to be too frightened to perform, to learn to do something else, or to be unable temporarily to recall what it had originally learned.

Since each of these explanatory notions was drawn from research based upon the simple retention paradigm, it is our judgment that attempts to validate any of them on the same paradigm are fruitless exereises in circularity. Clearly needed are differing methodological avenues through which the investigator might differentiate the several possible effects of convulsive shock. Our report is concerned with attempts to explore such an avenue.

The avenue we chose was incipient in the early studies of Horowitz \& Stone (1946) and Duncan (1948) and has been explicitly explored in studies by Davis (1962) and Dodd (1964), namely, how ECS interacts with interfering habits. To illustrate via the retrograde amnesic interpretation of ECS, any normally interfering habit that is immediately followed by a convulsive shock should be to some extent "forgotten"-and to the extent it is forgotten, better learning or retention of the normally-interfered-with habit should occur. Close scrutiny of the procedures and data of the above reports indicates that neither associative nor proactive interference is reduced by ECS (cf. Horowitz \& Stone, 1946; Dodd, 1964). However, the hours and days of time the rat Ss of these studies spent in attaining criterional performance during learning of a to-be-interfering habit was considerably longer than the retrograde reach most contemporary investigators are willing to attribute to ECS amnesia. We thus consider the question whether ECS can diminish associative or proactive interference as operationally moot, although one positive report with a conceptually similar measure should be mentioned. This is Greenough \& Schwitzgebel's (1966); ECS administered to rats after extinction of a lever-pressing habit was later followed by relatively high resistance to extinction.

In the study to be presented here, we turned to the retroactive inhibition paradigm with which Duncan (1948) was to find some, but not strong, evidence that ECS can at tenuate retroactive interference. The species and behavior studied were the same; we departed from Duncan's use of appetitive motivation and used a simple water maze after determining in pilot studies that an interpolated reversal habit is learned much more quickly therein and would therefore be temporally more within the reach of the hypothesized retrograde amnesic influence of a single ECS.

\section{METHOD}

A total of 40 adult albino rats, all males obtained from Holtzman, was initially trained to make a simple turning response (20 animals to the left side, 20 to the right) at the choice point of a single-unit, two-choice water maze (see Fig. 1). Maintained throughout the experiment on ad lib water and food, the animals were paired and alternately run to a given turn in daily measures of eight trials each. An error was tallied on each trial in which an animal swam into and contacted the cul-de-sac of the "wrong side"; motivation to escape was insured by cooling the maze water with chipped ice to a temperature of $14 \mathrm{deg} \mathrm{C}$, $\pm 2 \mathrm{deg}$. Criterion for mastery of the original turning response was errorless performance on all eight trials of the third day of training; in all, 29 of 40 met criterion. On the fourth day, the 29 animals underwent eight trials of reversal training; 14 rats that previously had learned to swim to the "left," now had to swim to the "right," and 15 learning "right" had to swim "left." Near the completion of these eight reversal trials, all of which required less than $10 \mathrm{~min}$ for a pair of animals to complete, a coin was flipped to determine which of the two animals would be shocked. The two animals were then individually wrapped in towels and gently held by one investigator while another attached leads with alligator clips to each animal's ears. Each experimental animal received a single application of $120 \mathrm{ac}$, $\mathrm{rms} V$ at $60 \mathrm{~Hz}$ for $0.5 \mathrm{sec}$, electronically timed; control animals were treated identically except that voltage was not applied. All animals receiving the shock treatment sustained tonic-clonic seizures lasting $60-100 \mathrm{sec}$. One of these animals failed to survive the treatment. Finally, on the fifth day, the remaining 28 animals underwent eight trials of retraining on their original habit. Errors were independently recorded by two investigators, both of

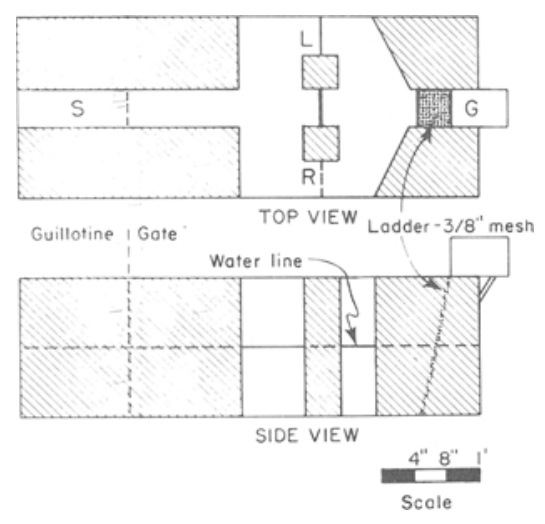

Fig. 1. Schematic drawing of water maze detailing start (S) and goal (G) areas and left (L) and right (R) choices. The maze was constructed of black, opaque Plexiglas except for the wire-mesh ladder and a sheet-metal goalbox. The top of the goalbox pivoted forward on a hinge to permit removal of a rat $S$. A removable sheet of black Plexiglas was inserted at the left or the right choice area to form a cul-de-sac. 


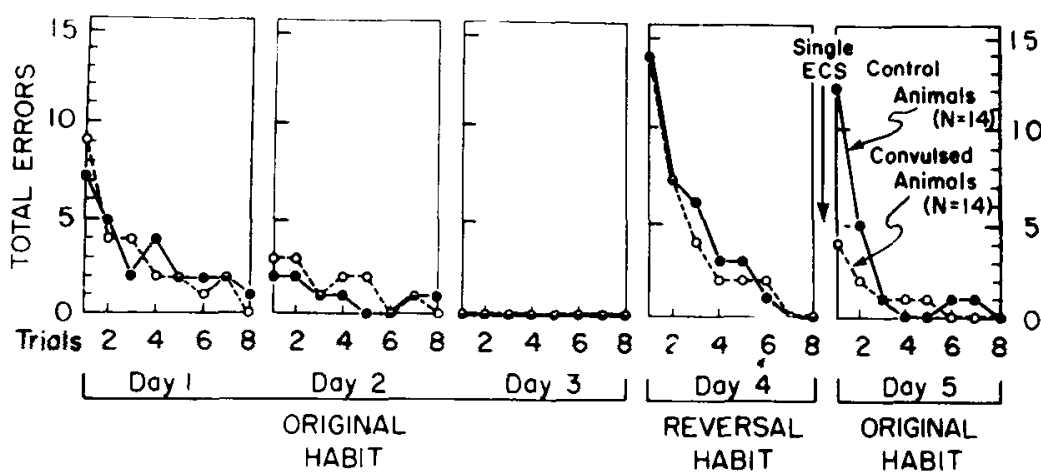

whom were naive to the experimental status of particular animals.

\section{RESULTS}

Figure 2 presents a graphical account of total errors made by 14 experimental and 14 control animals on each trial of the 5-day series. It is obvious by inspection that shocked animals as a group erred much less than control Ss on the first trial of Day 5 . Evaluated via Yates-corrected chi square $(7.14,1 \mathrm{df})$, this difference in retention performance is highly reliable $(p<.01)$. Similar chi square tests on all trials of Days 1 through 4 confirm the appearance of negligible differences between control and experimental animals prior to shock treatment ( $p s>.10)$. The same test applied to Trials 2 through 8 of Day 5 also resulted in ps greater than .10. A final statistical comparison involved the number of animals in each condition that made no errors during the eight trials of Day 5; only 1 control animal so performed, whereas 10 shocked animals performed errorlessly. The chi square of 9.58 at $1 \mathrm{df}$, reflecting this difference, is highly reliable $(\mathrm{p}<.005)$.

$$
\text { DISCUSSION }
$$

Electroconvulsive shock can interfere with a normally interfering habit: how does this datum fit with the several mechanisms proposed to account for behavioral effects of ECS? Since a single treatment produced the attenuation of interference, it is some what doubtful that conditioned-fear or competing-response mechanisms were operative. It is admitted that this interpretation is conjecture and will not be persuasive for the investigator with strong leanings toward fear-induction or competing-response theories; he will argue and we will agree that one-trial learning can occur to a variety of aversive stimuli. Moreover, even though single ECS treatments are widely believed to be free of prepotent aversive effects, this, too, is conjecture and should serve less as an argument than a point of departure for experimental test. One such test would be to substitute noxious footshock for ECS in the interference-with-interference paradigm; if single ECS is primarily an aversive stimulus, then other forms of aversive stimulation should produce a similar attenuation of retroactive interference.

If a single ECS is primarily an amnesic treatment, as we suspect, the consequences of ECS and aversive stimulation should be quite different. For example, start to goal area latencies (which were not rigorously recorded in the present study) would likely be much longer in footshocked animals during trials involving relearning of the original habit.

Assuming our finding was produced by a retrograde amnesia, it provides no leverage on the question of whether memory per se or retrieval of memory was impaired by ECS. A state-dependent (temporary amnesia, failure of retrieval) mechanism would posit that changes of brain excitability, rerouting of central nervous pathways, etc., occurred af ter the single ECS treatment and persisted into the relearning trials of Day 5. The original (and relatively overleamed) habit, and the interpolated reversal habit, would both be subject to retrieval impairment, but the overlearned habit would more likely generalize to recall. A purely amnesic (absolute amnesia) mechanism, on the other hand, would assume selective retrograde elimination of the memory trace of the interpolated habit.

On grounds of parsimony, an absolute amnesic mechanism would appear to be favored, but we are given to the belief that empirical tests and not the formal contrivance of Occam's razor should be decisive in settling theoretical issues. An example of such a test would be to give single ECS treatments to animals prior to their training on the interpolated reversal habit, but well after mastery of the original habit. Such prior treatment, if measures of relearning of the original habit were appropriately delayed, should be associated with strong, behaviorally defined attenuation of interference from the interpolated habit. This prediction is based upon the assumption that the interpolated habit would "dwell in the state-of-change" induced in the wake of the ECS, while the measure of recall of original learning would
Fig. 2. Total errors by experimental and control rats on each of eight daily trials across five consecutive daily measures in the water maze. Reversal of a left or a right turning response occurred during trials of the fourth day, and, immediately after the eighth trial, experimental animals received a single ECS treatment, control Ss, sham ECS.

involve optimal retrieval from the normal "field." An absolute and short-term retrograde amnesia would not, by definition, produce a lessening of interference.

In summary, we offer a finding of some curiosity value-a single ECS treatment closely following performance on a reversal task can reliably diminish normally resulting retroactive interference. We have further fit this finding to current conceptions of the modus operandi of ECS, but less to the end of favoring a particular theory than to suggest some new ways of empirically reaching an adequate account.

\section{REFERENCES}

ADAMS, H. E., \& LEWIS, D. J. Electroconvulsive shock, retrograde amnesia, and competing responses. Journal of Comparative \& Physiological Psychology, 1962, 55, 299-301.

COONS, E. E., \& MILLER, N. E. Conflict versus consolidation of memory traces to explain "retrograde amnesia" produced by ECS. Journal of Comparative \& Physiological Psychology, 1960, 53, 524-531.

DAVIS, K. B. Delayed electroconvulsive shock and maze retention deficits in rats. Unpublished Master's thesis, University of Missouri at Kansas City, 1962.

DODD, D. H. Water maze performance of rats in a proactive interference design: The effects of visual occlusion and convulsive shock. Unpublished Master's thesis, University of Missouri at Kansas City, 1964

DUNCAN, C. P. Habit reversal induced by electroshock in the rat. Journal of Comparative \& Physiological Psychology, 1948, 41, 11-16.

DUNCAN, C. P. The retroactive effect of electroshock on learning. Journal of Comparative \& Physiological Psychology, 1949, $42,32-44$.

GLICKMAN, S. E. Perseverative neural processes and consolidation of the neural trace. Psychological Bulletin, 1961, 58, 218-233.

GREENOUGH, W. T., \& SCHWITZGEBEL, R. L. Effects of a single ECS on extinction of a bar-press. Psychological Reports, 1966, 19, $1227-1230$.

HOROWITZ, M. W., \& STONE, C. P. The ease of learning a new habit in relation to the disorganization of an inter ${ }^{f_{e}}$ ring habit as affected by electroconvulsive shock in the rat. American Psychologist, 1946, $1,449$.

LEWIS, D. J., \& MAHER, B. A. Electroconvulsive shock and inhibition: Some problems reconsidered. Psychological Review, 1966, 73, 388-392.

McGAUGH, J. L., \& PETRINOVICH, L. F. Neural consolidation and electroconvulsive shock reexamined. Psychological Review, 1966, 73 , 382-387. 
MLIVER, A. H., \& NIELSON, H. C. Effects of electroconvulsive shock and grid shock on open field behavior. Journal of Comparative \& Physiological Psychology, 1966, 62, 102-107.

NIELSON, H. C. Evidence that electroconvulsive shock alters memory retrieval rather than memory consolidation. Experimental Neurology, 1968, 20, 3-20.

NIELSON, H. C., JUSTESEN, D. R., \& PORTER, P. B. Effects of anticonvulsant drugs upon patterns of seizure discharge and brain thresholds: Some implications for memory mechanisms. Psychological Reports, 1969, 23, 843-850.

\section{NOTES}

1. This study was supported by 8200 Research Funds from the U.S. Veterans Administration. Mrs. Kay Wahl and Mr. Harold Bowen of the V. A. Hospital's medical illustration service are warmly acknowledged for their preparation of the figures.

2. Present address: Department of Psychology, University of Utah, Salt Lake City, Utah 84112.

\section{Magnesium pemoline: Different effects with different subject stocks'}

\author{
JOHN A. CORSON, McGill University, \\ Montreal 110, Canada
}

Twenty-four Sprague-Dawley and 24 Long-Evans rats were tested in a situation requiring a pole-climbing response. Half of the members of each stock were injected with magnesium pemoline and half with vehicle. Magnesium pemoline had a transient interfering effect on the learning of the Sprague-Dawley animals and prolonged the extinction of the Long-Evans animals. These results suggest that the eventual description of the behavioral effects of magnesium pemoline will be in terms of a matrix involving variations in stock of S and type of task.

Magnesium pemoline (MP) has been reported to stimulate brain ribonucleic acid polymerase activity (Glasky \& Simon, 1966) and to improve the performance of a shock-motivated response by rats (Plotnikoff, 1966). There has been a controversy over the existence of the biochemical effect of MP (Morris, Aghajanian, \& Bloom, 1967; Stein \& Yellin, 1967; Brink \& Stein, 1967), which is confused by procedural differences. There have also been controversies concerning the behavioral effects of MP. At the human level, the controversy has concerned both the existence and explanation of the effects of MP (Smith, 1967), while at the animal level, the problem has been primarily one of explanation. At the animal level, the explanation proposed by Plotnikoff (1966) was in terms of enhancement of learning and memory, while other workers (Frey \& Polidora, 1967; Beach \& Kimble, 1967) have proposed that MP produced behavioral effects by reducing the tendency to freeze or, similarly, by energizing or stimulating the S. Between these general classes of explanation, it seems that a much stronger case can be made for MP having a stimulating effect than for its having the effect of enhancing learning and memory. For example, recent reports show that MP produces increased motor activity (Boitano \& Boitano, 1967) and a deficit in passive-avoidance learning, where animals are required to inhibit a response (Gurowitz, Lubar, Ain, \& Gross, 1967). However, the picture at this point is confused by differences among the various reports in such variables as stock of $S$ and the type of task used to assess the effect of MP.

We recently reported (Corson, 1967) a series of studies of the behavioral effect of MP on the performance of rats in a variety of tasks. In several of these studies we ran our Ss through a series of shock-motivated tasks ranging from simple escape to pattern discrimination. This series of tasks was used

\section{Table 1}

Effect of Magnesium Pemoline on Leaming and Extinction Performance of Naive Long-Evans and Sprague-Dawley Rats in a Shock-Motivated Pole-Climbing Task

\begin{tabular}{|c|c|c|c|c|c|c|c|c|c|c|}
\hline \multirow[b]{2}{*}{ Measure } & \multicolumn{4}{|c|}{ Long-Evans } & \multirow[b]{2}{*}{$\mathrm{p}^{*}$} & \multicolumn{4}{|c|}{ Sprague-Dawley } & \multirow[b]{2}{*}{$\mathrm{p}^{*}$} \\
\hline & $\begin{array}{l}\text { Experi } \\
\text { Median }\end{array}$ & $\begin{array}{c}\text { nental } \\
\text { Range }\end{array}$ & $\begin{array}{r}\text { Contr } \\
\text { Median }\end{array}$ & $\begin{array}{l}\text { rol } \\
\text { Range }\end{array}$ & & $\begin{array}{l}\text { Experir } \\
\text { Median }\end{array}$ & $\begin{array}{l}\text { imental } \\
\text { Range }\end{array}$ & $\begin{array}{r}\text { Cont } \\
\text { Median }\end{array}$ & $\begin{array}{l}\text { trol } \\
\text { Range }\end{array}$ & \\
\hline $\begin{array}{l}\text { Number of trials } \\
\text { to first climb }\end{array}$ & Is 2 & $1-3$ & 1.5 & $1-7$ & $>0.1$ & 6 & $1-20+$ & 2 & $1-10$ & $<.05$ \\
\hline $\begin{array}{l}\text { Number of climbs } \\
\text { on Day } 1\end{array}$ & bs 9 & $7-10$ & 9.5 & $4-10$ & $>0.1$ & 4.5 & $0-10$ & 8 & $1-9$ & $<0.1$ \\
\hline $\begin{array}{l}\text { Mean hold durati } \\
\text { of successful } \\
\text { climbs on Day } 1\end{array}$ & 22.9 & $5.5-34.4$ & 24.2 & $4.2-42.2$ & $>0.1$ & 10.0 & $2.0-34.7$ & 18.7 & $3.0-33.6$ & $>0.1$ \\
\hline $\begin{array}{l}\text { Number of climbs } \\
\text { on Day } 2\end{array}$ & bs 10 & $10-10$ & 10 & $7-10$ & $>0.1$ & 8.5 & $0-10$ & 10 & $7-10$ & $>0.1$ \\
\hline $\begin{array}{l}\text { Mean hold duratio } \\
\text { of successful } \\
\text { climbs on Day } 2\end{array}$ & 29.1 & $13.5-44.5$ & 528.7 & $60-49.9$ & $>0.1$ & 13.2 & 4.9-32.5 & 30.1 & $4.9-44.9$ & $>0.1$ \\
\hline $\begin{array}{l}\text { Number of climbs } \\
\text { on extinction } \\
\text { Day } 1\end{array}$ & 9.5 & $4-10$ & 4 & $0-10$ & $<0.2$ & 2.5 & $0-10$ & 0 & $0-10$ & $>0.1$ \\
\hline $\begin{array}{l}\text { Number of climbs } \\
\text { on extinction } \\
\text { Day } 2\end{array}$ & 6.5 & $0-10$ & 0 & $0-10$ & $<.05$ & 0 & $0-10$ & 0 & $0-10$ & $>0.1$ \\
\hline
\end{tabular}

*The $p$ values were calculated with the two-tailed Mann-Whitney U test.

Two experimental Sprague-Dawley $S$ s made no responses during learning or extinction, but a separate analysis with these animals omitred did not change the significance levels shown here. 